\title{
Fenton-like degradation of Bisphenol A catalyzed by mesoporous $\mathrm{Cu} / \mathrm{TUD}-1$
}

Muthusamy P. Pachamuthu, ${ }^{1}$ Sekar Karthikeyan, ${ }^{2}$ Rajamanickam Maheswari, ${ }^{3}$ Adam F. Lee, ${ }^{2}$ and Anand Ramanathan*3

${ }^{1}$ Department of Chemistry, Bannari Amman Institute of Technology, Sathyamangalam, Erode 638401, India

${ }^{2}$ European Bioenergy Research Institute, Aston University, Aston Triangle, Birmingham B4 7ET, United Kingdom

${ }^{3}$ Center for Environmentally Beneficial Catalysis (CEBC), The University of Kansas, Lawrence, KS 66047, USA

*Corresponding author. E-Mail: anand@ku.edu (A.R); Tel.: +1-785-864-6146; Fax: +1-785-864-6051. 


\begin{abstract}
A family of copper oxide catalysts with loadings spanning 1 to $5 \mathrm{wt} \%$ were dispersed on a three dimensional, mesoporous TUD-1 silica through a hydrothermal, surfactant-free route employing tetraethylene glycol as a structure-directing agent. Their bulk and surface properties were characterized by $\mathrm{N}_{2}$ physisorption, XRD, DRUVS, EPR, TEM and Raman spectroscopy, confirming the expected mesoporous wormhole/foam support morphology and presence of well-dispersed CuO nanoparticles ( 5-20 nm). The catalytic performance of Cu/TUD-1 was evaluated as heterogeneous Fenton-like catalysts for Bisphenol A (BPA) oxidative degradation in the presence of $\mathrm{H}_{2} \mathrm{O}_{2}$ as a function of $\left[\mathrm{H}_{2} \mathrm{O}_{2}\right]$, and CuO loading. Up to $90.4 \%$ of 100 ppm BPA removal was achieved over 2.5 wt\% Cu/TUD-1 within 180 min, with negligible Cu leaching into the into the treated water.
\end{abstract}

\title{
Keywords:
}

Copper; TUD-1; Fenton-like oxidation; mesoporous solid; Bisphenol A; excitation-emission matrix. 


\section{Introduction}

Fenton type advanced oxidation processes (AOPs) are one of the most efficient and widely utilized wastewater treatments [1]. Heterogeneous Fenton agents have many advantages over their homogeneous counterpart for the degradation of organic pollutants in waste streams, with many studies focused on the development of iron-derived heterogeneous Fenton catalyst systems [2-11]. Hartman et al. have reviewed the development and application of such Fe-containing porous catalysts for wastewater treatment [12]. Fe-ZSM-5 [13], Fe(II)/meso- $\mathrm{Al}_{2} \mathrm{O}_{3}$ [14], $\mathrm{Fe}(\mathrm{III})$ oxide/carbon [15], magnetic $\alpha-\mathrm{Fe}_{2} \mathrm{O}_{3} / \mathrm{MCM}-41$ [16], Fe/SBA-15 [17], and Fe/TUD-1 [18] are all reported to exhibit excellent degradation activity towards various organic pollutants.

$\mathrm{Cu}^{2+} / \mathrm{Cu}^{+}$-containing materials offer interesting alternative catalysts, since they also exhibit Fenton-like oxidation activity [19]. A range of copper catalysts including CuFe/ZSM-5 [20], stabilized CuO nanoparticles [21], $\mathrm{CuO} / \mathrm{CeO}_{2}$ [22], Cu-functionalized titanate nanotubes [23] and $\mathrm{CuFeO}_{2}$ [24] have all been explored for their degradation ability towards various water pollutants. Copper promoted mesoporous materials such as MCM-41[25], mesoporous activated carbon [26], and copper-doped mesoporous silica microspheres [27] have also been reported for Fenton- or photo-Fenton-like pollutant degradation. Nevertheless, very few copper promoted mesoporous catalysts have been systematically studied for wastewater treatment to date.

We reported recently on the preparation of Cu/TUD-1 [28], based upon TUD (Technische Universiteit Delft), a mesoporous silica that can be prepared by an environmentally friendly route. The formation of Cu-atrane and silatrane complexes during TUD-1 synthesis $[28,29]$ facilitates a high dispersion of framework Cu species in the silica network. We have also employed tetraethylene glycol (TEG) as 
structure directing agent for TUD-1 (in place of triethanalomine) to prepare various metal incorporated TUD-1 materials [30-32].

Despite increasing environmental legislation and public awareness, many organic compounds are still discharged directly into water resources, especially in low and middle-income countries [33, 34]. Bisphenol A (BPA; 2,2-bis-(4-hydroxy phenyl)-propane) is one such endocrine disrupter [34-37] prevalent in different biospheres regions (e.g. water and soil sediments) of Tamil Nadu, India [34,38]. As a result of BPA's detrimental health impact on humans and animals several approaches have been developed to degrade it within wastewater [39-42].

Here we extend the application of our TEG-directed synthesis of TUD-1 to incorporate $\mathrm{Cu}$, and demonstrate its application as a Fenton-like heterogeneous catalyst for BPA degradation.

\section{Experimental}

\subsection{Synthesis of $\mathrm{Cu} / T U D-1$}

Cu/TUD-1 catalysts with varying Si:Cu ratios of 100, 50 and 25 (corresponding to $\mathrm{Cu}$ loadings of 1, 2 and 4 wt\% respectively) were prepared using TEG as a template adapting our previous methodology [30-32]. In brief, $10 \mathrm{~g}$ of tetraethyl orthosilicate (TEOS) and the requisite amount of copper nitrate, $\mathrm{Cu}\left(\mathrm{NO}_{3}\right)_{2} \cdot 3 \mathrm{H}_{2} \mathrm{O}$, in water were stirred for 30 minutes. Subsequently, $7 \mathrm{~mL}$ of TEG was added dropwise and stirred for $1 \mathrm{~h}$. Finally, tetraethylammonium hydroxide (TEAOH, 35\%, 9 g) was added and stirring continued for $2 \mathrm{~h}$. The resulting gel was aged at $30^{\circ} \mathrm{C}$ and dried at $100^{\circ} \mathrm{C}$ for $24 \mathrm{~h}$, then transferred into a Teflon-lined autoclave and heated for $6 \mathrm{~h}$ at $160{ }^{\circ} \mathrm{C}$. The resultant solid was calcined at $600^{\circ} \mathrm{C}$ for $10 \mathrm{~h}$ in air to remove the template and other organic components. The final $\mathrm{Cu} / \mathrm{TUD}-1$ catalysts contained 0.9, 2.5 and $5.4 \mathrm{wt} \% \mathrm{Cu}$ from elemental analysis. 


\subsection{Characterization}

Powder X-ray diffraction (XRD) measurements were carried out on a Bruker D8 instrument using Cu $\mathrm{K}_{\alpha}$ radiation $\left(\lambda=1.5418 \hat{\text { Á). }} \mathrm{N}_{2}\right.$ physisorption was performed on a Micromeritics ASAP 2020 porosimeter at 196 ㄷ. Sample morphology was investigated via scanning electron microscopy (SEM) using FEI ESEM Quanta 200 microscope, and high-resolution transmission electron microscopy (HRTEM) using a JEOL 3010 instrument. Diffuse reflectance UV-Vis spectra (DRUVS) were recorded between $200-800 \mathrm{~nm}$ on a Thermoscientific Evolution 600 instrument using a $\mathrm{BaSO}_{4}$ reference. Raman spectra were measured on a Bruker FT-Raman 1000R instrument with a $1064 \mathrm{~nm}$ excitation source. Electron spin resonance (ESR) spectra were recorded on a JEOL JES FA-300 spectrometer at room temperature. EPR spin trapping of $\mathrm{Cu} / \mathrm{TUD}-1$ was obtained at room temperature using a quartz liquid flat cell (Wilmad WG-812-Q) in a TE102 cavity of a Bruker ESP 300E spectrophotometer. The spectrophotometer was operated at a microwave frequency of $9.399 \mathrm{GHz}$, with microwave power of $3.188 \mathrm{~mW}$, modulation frequency of 100 $\mathrm{kHz}$ and modulation amplitude of $3.0 \mathrm{G}, 3200 \mathrm{G}$ center field, and a sweep width of $500 \mathrm{G}$ and sweep time of 20.972 s. X-ray photoelectron spectroscopy (XPS) was undertaken on an Omicron ESCA probe spectrometer with $\mathrm{Al} \mathrm{K}_{\alpha}$ radiation $(1486.7 \mathrm{eV})$. Energy referenced to adventitious carbon at $284.9 \mathrm{eV}$ binding energy. Copper content was determined by inductively coupled plasma-optical emission spectroscopy (ICP-OES) on a Perkin Elmer OES Optima 5300 DV spectrometer.

\subsection{Oxidative degradation of BPA}

BPA degradation was performed in a $500 \mathrm{~mL}$ polypropylene bottle under magnetic stirring. $100 \mathrm{ml}$ of a $100 \mathrm{ppm}$ aqueous BPA solution was prepared with an initial $\mathrm{pH}$ of 6.45 . The $\mathrm{pH}$ was adjusted to 3.5 using $1 \mathrm{~N} \mathrm{H}_{2} \mathrm{SO}_{4}$ and $0.1 \mathrm{~g}$ of catalyst added to the BPA solution. Various amounts of $\mathrm{H}_{2} \mathrm{O}_{2}$ (between $20 \mathrm{mM}$ to $100 \mathrm{mM}$ ) were then added to initiate oxidative degradation. $1 \mathrm{~mL}$ aliquots of the reaction solution were 
periodically withdrawn for spectrophotometric UV-Vis analysis [12]. Copper leaching tests were conducted on filtered Cu/TUD-1 catalysts post-reaction by atomic absorption on a Shimadzu AA spectrophotometer. Fluorescence excitation/emission spectra were recorded using a Varian/CARY fluorescence spectrophotometer under 3D mode with an excitation wavelength between 200-600 nm with a step size of $5 \mathrm{~nm}$ using a quartz cuvette with $1 \mathrm{~cm}$ path length.

\section{Results and discussions}

\subsection{Characterizations of Cu/TUD-1}

Low angle XRD patterns of the $0.9 \mathrm{wt} \% \mathrm{Cu} /$ TUD-1 (Figure 1a) exhibited a single weak and broad reflection around $0.9^{\circ}$, also present in undoped TUD-1 prepared via the same route (Figure S1). The lack of additional reflections indicated a disordered arrangement of mesopores, commonly observed for metal incorporated TUD-1 $[30-32,43,44]$. The absence of this low angle reflection for 0.25 and $5 \mathrm{wt} \%$ CU/TUD-1 indicates that this disorder increased with $\mathrm{Cu}$ loading. Wide angle XRD patterns of all Cu/TUD1 samples exhibited a broad reflection between $15-30^{\circ}$ arising from the amorphous silica support, and sharp reflections characteristic of a crystalline $\mathrm{CuO}$ phase at $35.5^{\circ}$ and 38.60 whose intensity increased with Cu loading associated with an increase in mean crystallite diameter (as estimated by Scherrer peak width analysis) from 5 to $20 \mathrm{~nm}$. 

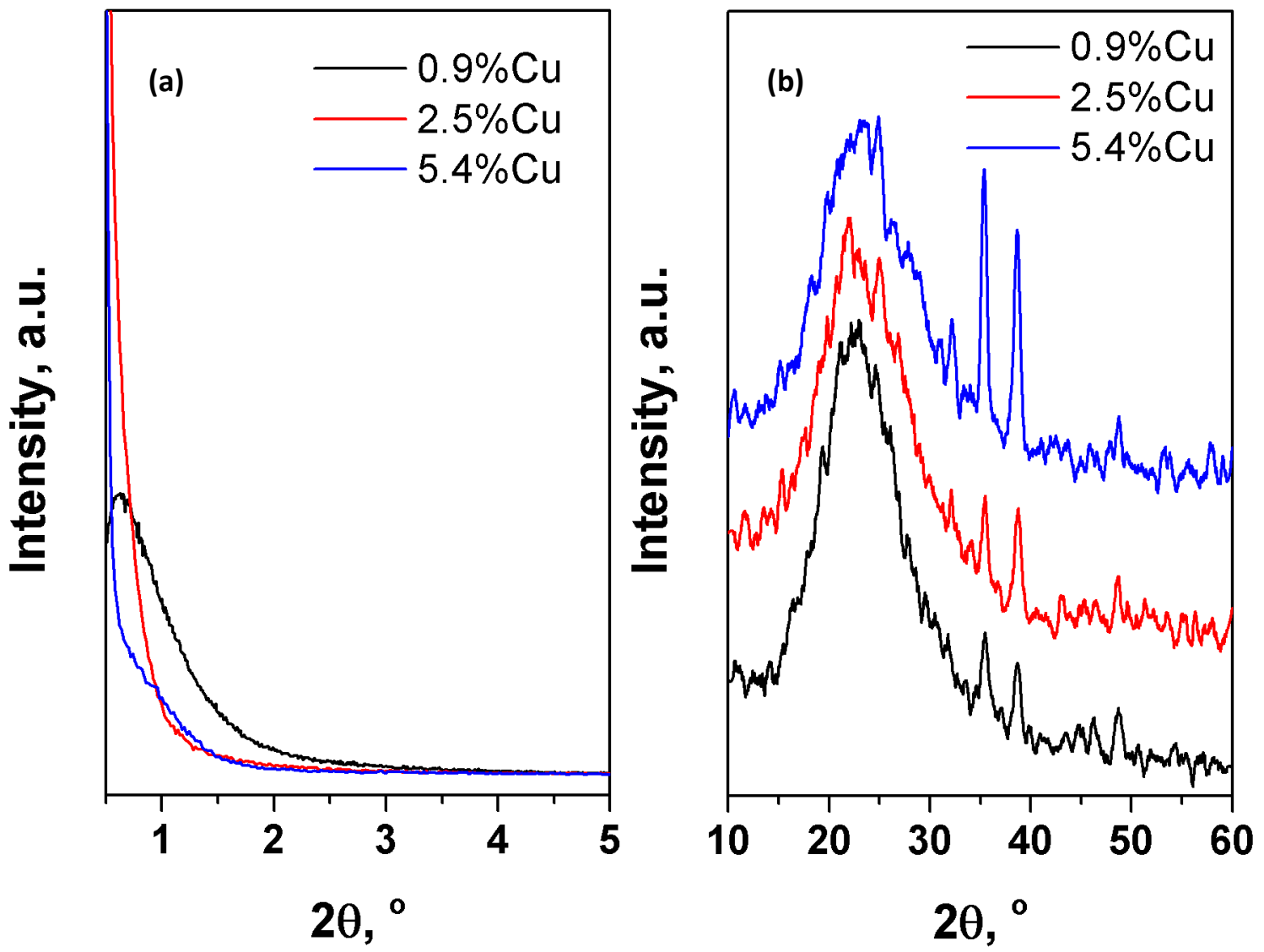

Figure 1. (a) Low and (b) wide angle powder XRD patterns of $\mathrm{Cu} / T U D-1$

The mesoporous nature of Cu/TUD-1 was apparent from nitrogen porosimetry which revealed type IV isotherms with $\mathrm{H} 2$ type hysteresis loops for all copper loadings (Figure 2), as expected for TUD-1 type wormhole pore architectures. Corresponding BET surface areas, mean BJH pore diameters and mesopore volumes are reported in Table 1, and were similar to an undoped TUD-1 and approximately independent of $\mathrm{Cu}$ loading, comparable to our previous TEG-templated MnTUD-1, ZrTUD-1 and CoTUD-1 materials [30-32].

Table 1. Physical characterization of different Cu/TUD-1 catalysts

\begin{tabular}{cccc}
\hline Cu loading & $S_{\mathrm{BET}}{ }^{\mathrm{b}}$ & $d_{\mathrm{P}, \mathrm{BJH}}{ }^{\mathrm{c}}$ & $V_{\mathrm{p}, \mathrm{BJH}}{ }^{\mathrm{d}}$ \\
$/ \mathrm{wt}^{\mathrm{a}}$ & $\mathrm{m}^{2} / \mathrm{g}$ & $/ \mathrm{nm}$ & $/ \mathrm{cm}^{3} / \mathrm{g}$ \\
\hline
\end{tabular}




\begin{tabular}{cccc}
\hline 0 & 490 & 6.0 & 1.72 \\
0.9 & 437 & 7.8 & 1.86 \\
2.5 & 425 & 6.7 & 1.39 \\
5.4 & 393 & 8.1 & 1.98 \\
\hline
\end{tabular}

${ }^{\mathrm{a}}$ From ICP-OES analysis; ${ }^{\mathrm{b}}$ specific surface area; ${ }^{\mathrm{c}}$ mean mesopore diameter; ${ }^{\mathrm{c}}$ mesopore volume

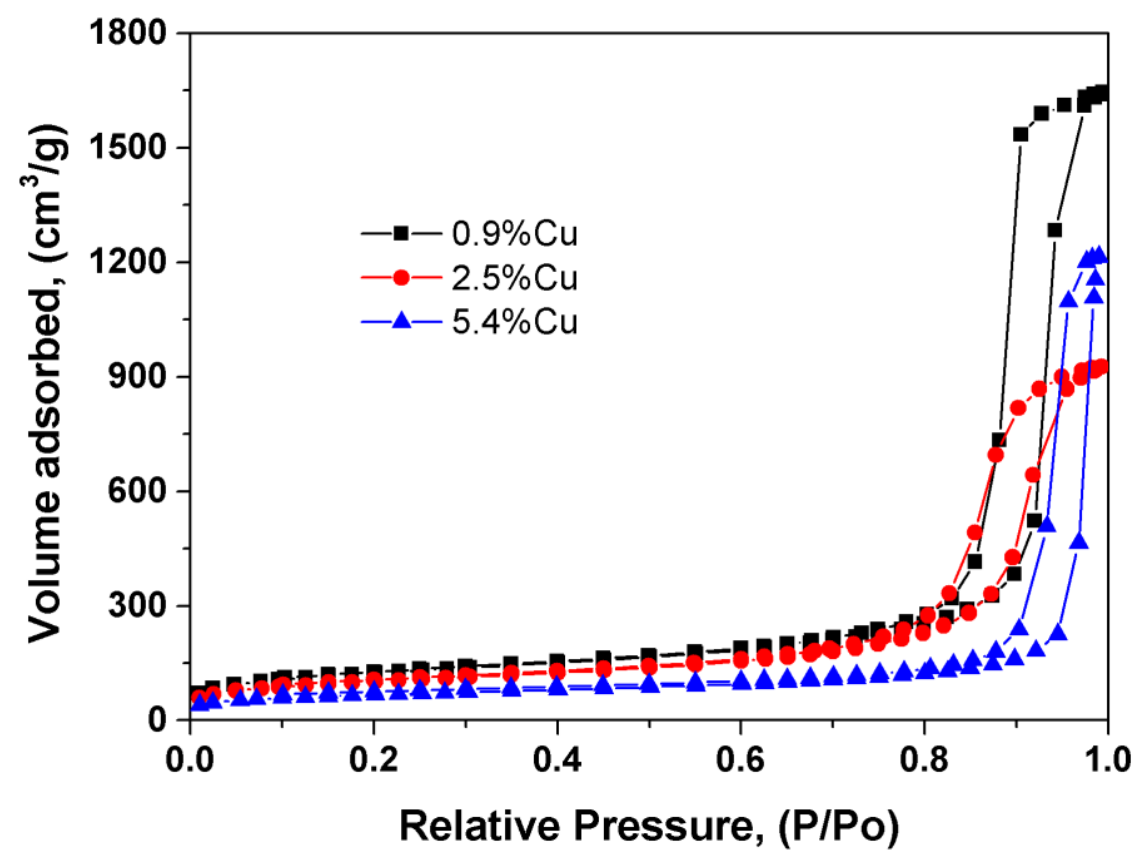

Figure 2. $\mathrm{N}_{2}$ adsorption-desorption isotherms of $\mathrm{Cu} / \mathrm{TUD}-1$

DRUV spectra of Cu/TUD-1 exhibited absorption bands at 235, 310 and 350-800 nm (Figure 3a), similar to those for Cu/TUD-1 prepared by a TEA template route [28]. The band at $235 \mathrm{~nm}$ is assigned to ligand-to-metal charge transfer (LMCT) from an $\mathrm{O}^{2-}$ to an isolated $\mathrm{Cu}^{2+}$ ion in a tetrahedral coordination, and that at $310 \mathrm{~nm}$ arises from CuO oligomers. Strong absorption between 350 and $800 \mathrm{~nm}$ is attributed to bulk $\mathrm{CuO}$ (copper in a pseudo-octahedral environment), with the intensity of this band increasing with $\mathrm{Cu}$ concentration indicating the growth of extra-framework $\mathrm{CuO}$ particles in Cu/TUD-1 consistent 
with XRD. FT-Raman spectra of Cu/TUD-1 revealed two sharp and one broad peaks at 295, 342 and 620 $\mathrm{cm}^{-1}$ respectively for all Cu loadings (Figure $3 b$ ), assigned to the $A_{g}$ and $2 \mathrm{~B}_{\mathrm{g}}$ Raman active modes of CuO [28] in agreement with XRD and DRUVS results.
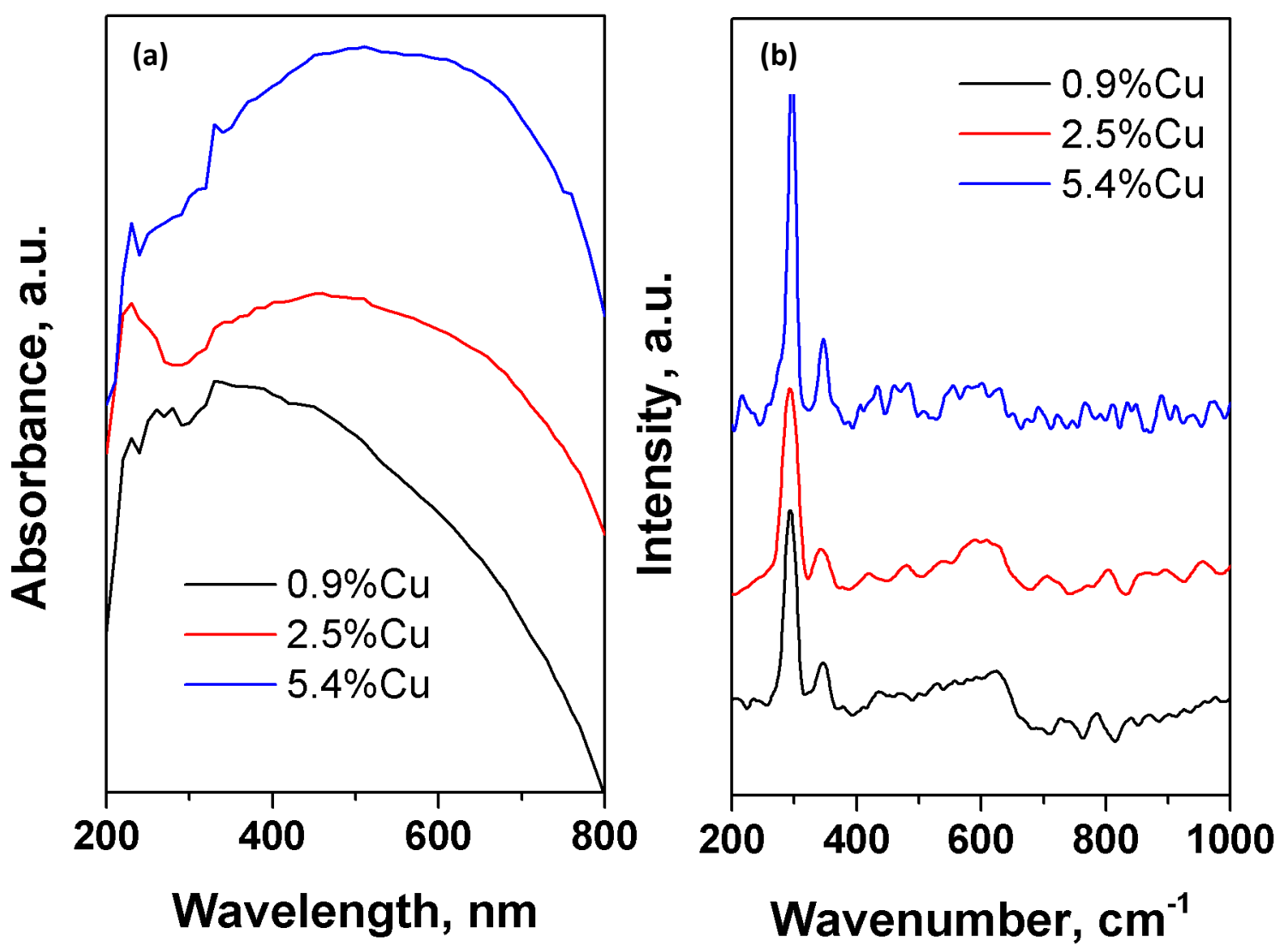

Figure 3. (a) DRUV and (b) Raman spectra of Cu/TUD-1

EPR spectra of $\mathrm{Cu} / \mathrm{TUD}-1$ at room temperature confirmed the presence of isolated $\mathrm{Cu}^{2+}$ ions and oligonuclear $\mathrm{CuO}$ species (Figure 4). Bulk CuO (the majority species for high copper loadings) in samples is however EPR silent due to strong dipole-dipole interactions of copper ions in the crystal lattice. A single, intense axially symmetric peak was observed for all Cu/TUD-1 samples, whose intensity increased from the 0.9 to $2.5 \mathrm{wt} \%$ samples, before decreasing for the highest copper loading. This indicates that 2.5 wt\% Cu/TUD-1 contained the highest concentration of isolated $\mathrm{Cu}^{2+}$ and oligomeric $\mathrm{CuO}$ species. 


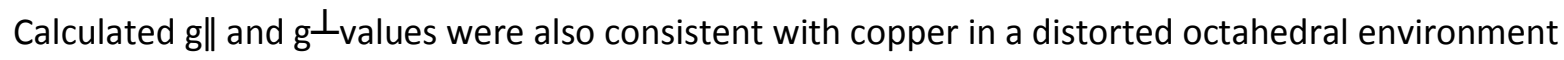
[28]. Such EPR signals are anticipated to correlate with strong free electron behavior in these Cu/TUD-1 materials.

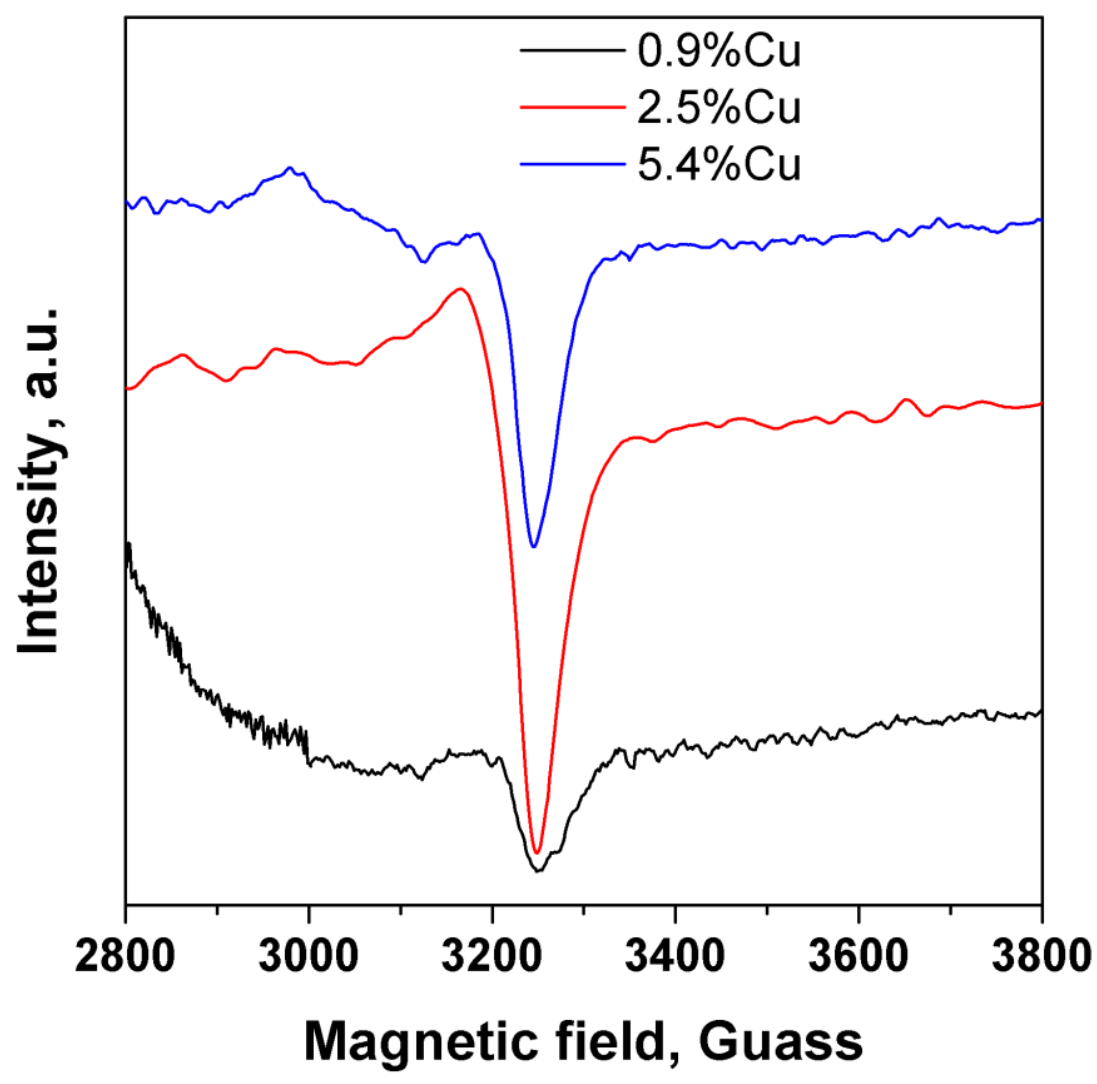

Figure 4. EPR spectra of Cu/TUD-1

The $\mathrm{Cu} 2 \mathrm{p}$ XP spectrum of $2.5 \mathrm{wt} \% \mathrm{Cu} / \mathrm{TUD}-1$ (Figure S2) revealed a spin-orbit split doublet with $\mathrm{Cu}$ $2 \mathrm{p}_{3 / 2}$ and $\mathrm{Cu} 2 \mathrm{p}_{1 / 2}$ binding energies of $935.3 \mathrm{eV}$ and $955.3 \mathrm{eV}$ respectively. The $\mathrm{Cu} 2 \mathrm{p}_{3 / 2}$ asymmetric peak could be fitted with two components at $932.8 \mathrm{eV}$ and $935.7 \mathrm{eV}$, assigned to bulk $\mathrm{CuO}$ and isolated $\mathrm{Cu}^{2+}$ species in octahedral sites respectively [23, 28].

SEM and TEM micrographs of $2.5 \mathrm{wt} \% \mathrm{Cu} / \mathrm{TUD}-1$ are shown in Figure 5. SEM revealed micron-sized irregular (silica) particles (Figure 5a), while the presence of a disordered, wormhole-like pore network typical of TUD-1 type materials was observed by TEM (Figure 5b). Complementary SEM-EDX analysis 
(not shown) confirmed bulk Cu loadings for all Cu/TUD-1 samples in good agreement with those from ICP-OES analysis.

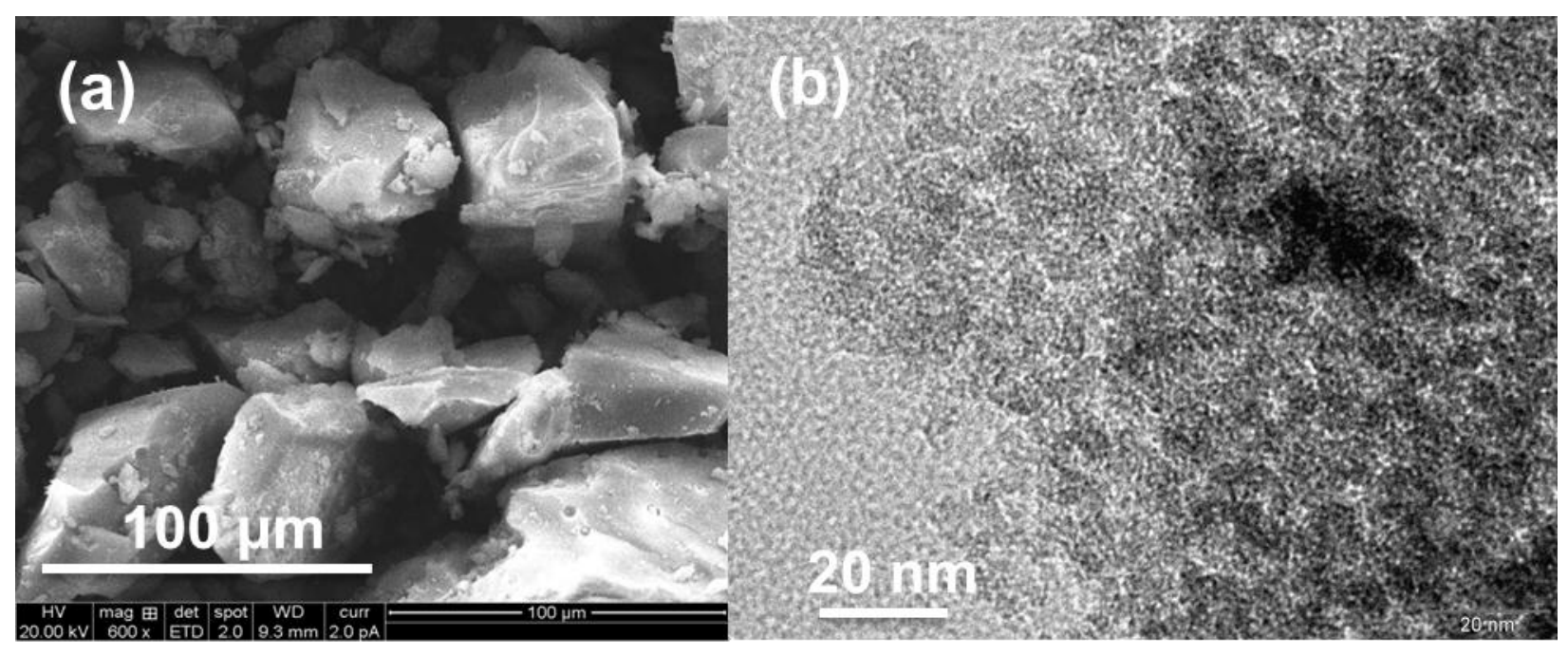

Figure 5. (a) SEM and (b) TEM micrographs of $2.5 \mathrm{wt} \% \mathrm{Cu} / \mathrm{TUD}-1$

\subsection{Cu/TUD-1 catalyzed degradation of Bisphenol A}

The catalytic performance of Cu/TUD-1 materials towards Fenton-like oxidative degradation of BPA was subsequently investigated via UV-Vis spectroscopy in the presence of $\mathrm{H}_{2} \mathrm{O}_{2}$. Illustrative timedependent spectra are shown in Figure 6 for 2.5 wt\% Cu/TUD-1, highlighting the principal UV-Vis absorptions of BPA at $220 \mathrm{~nm}$ and $280 \mathrm{~nm}$ (due to aromatic phenolics) whose intensities decreased monotonically with time due to BPA degradation. Initial BPA degradation activity (determined from the 280 absorbance) was approximately independent of $\mathrm{Cu}$ loading, for the first $30 \mathrm{~min}$ of reaction during which linearity was maintained (Figure 7). However, significant differences were observed in the limiting degree of BPA removal, with a maximum observed for the $2.5 \mathrm{wt} \% \mathrm{Cu} / \mathrm{TUD}-1$ of $90.4 \%$, compared with only $68 \%$ and $78 \%$ for 5.4 wt\% Cu/TUD-1 and 0.9 wt\% Cu/TUD-1 respectively (we note that all Cu/TUD-1 samples surpassed bulk $\mathrm{CuO}$ which only removed $40 \%$ BPA under identical conditions). The results 
suggest a strong correlation between the genesis of isolated $\mathrm{Cu}^{2+}$ ions and oligonuclear $\mathrm{CuO}$ clearly during synthesis of $\mathrm{Cu} /$ TUD-1 and BPA degradation activity with $\mathrm{H}_{2} \mathrm{O}_{2}$, although the possibility of pore blockage by large CuO crystallites in the 5 wt \% Cu/TUD-1 sample must also be considered [28]. Control experiments in the absence of $\mathrm{H}_{2} \mathrm{O}_{2}$ showed that BPA adsorption (versus its oxidation) accounted for $<10$ $\%$ of the overall observed removal for all catalysts, confirmed through comparison with undoped TUD-1 for which a similar level of BPA removal was observed with or without $\mathrm{H}_{2} \mathrm{O}_{2}$ due simply to adsorption of the organic.

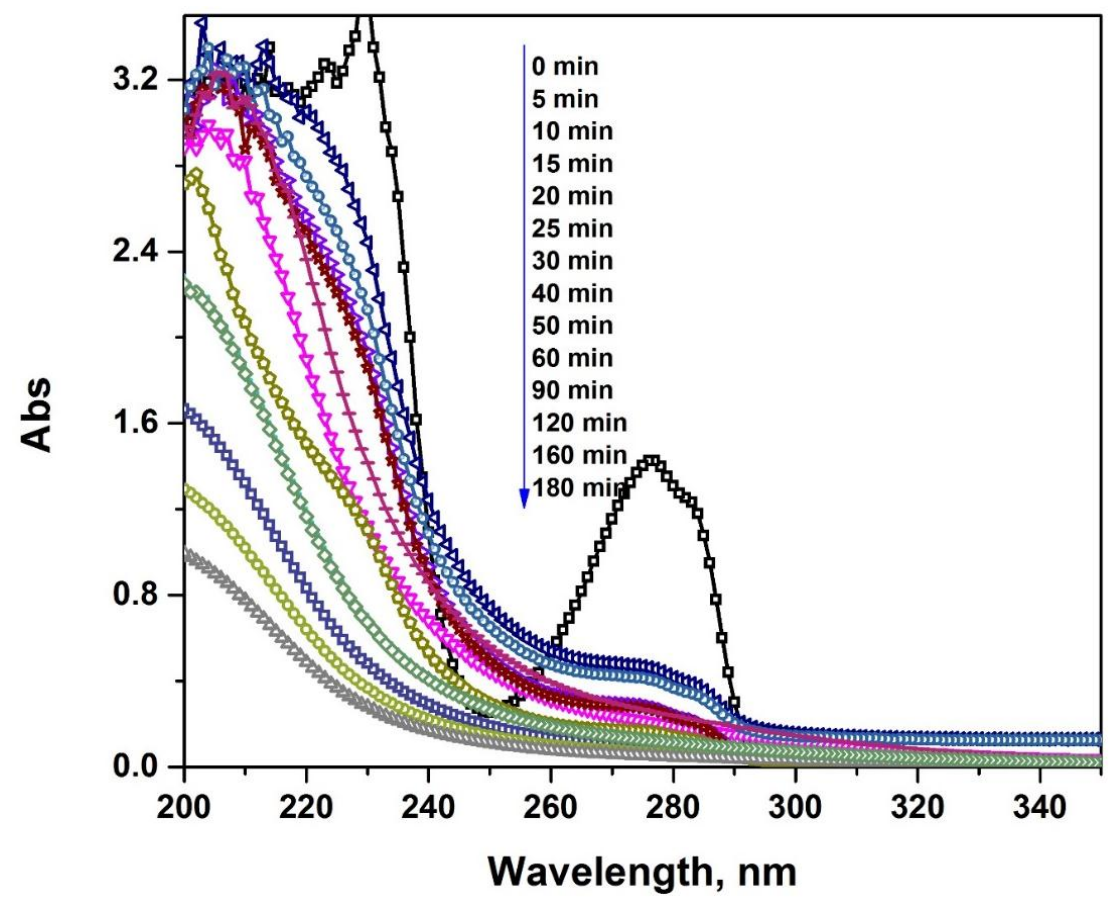

Figure 6. UV-Vis spectra showing BPA oxidative degradation over $2.5 \mathrm{wt} \% \mathrm{Cu} / \mathrm{TUD}-1$. Reaction conditions: 100 ppm BPA, 0.1 g catalyst, $90 \mathrm{mM} \mathrm{H}_{2} \mathrm{O}_{2}$. 


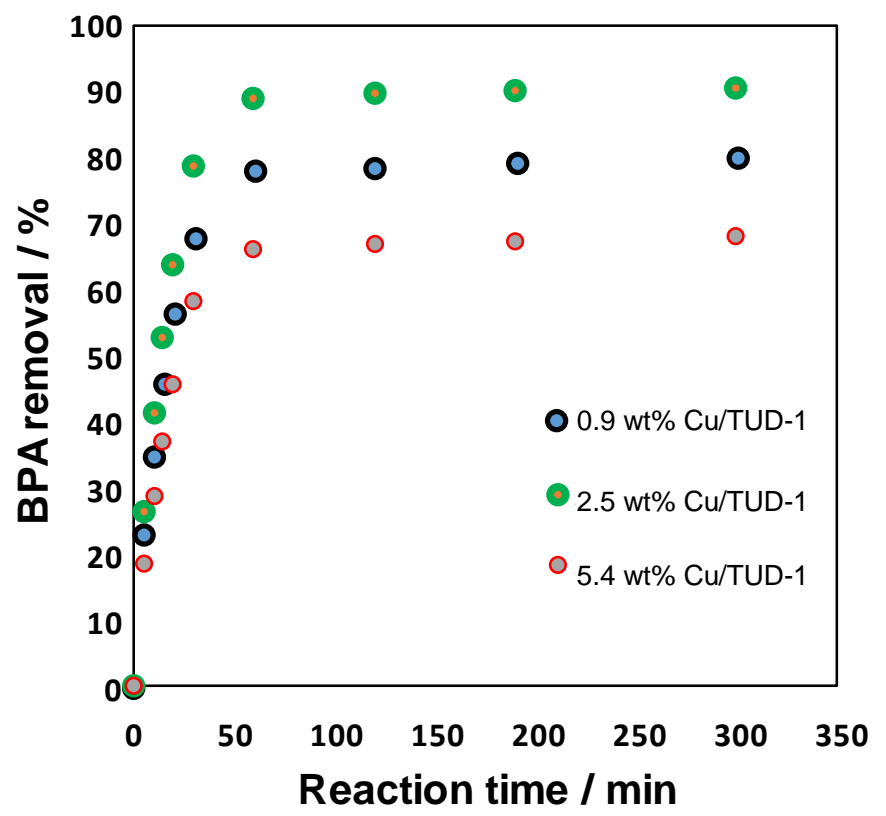

Figure 7. BPA removal over Cu/TUD-1. Reaction conditions: 100 ppm BPA, 0.1 g catalyst, $90 \mathrm{mM} \mathrm{H}_{2} \mathrm{O}_{2}$.

The influence of $\left[\mathrm{H}_{2} \mathrm{O}_{2}\right]$ on BPA degradation over $\mathrm{Cu} / \mathrm{TUD}-1$ was also explored as a function of copper loading (Table 2). Only $8 \%$ BPA removal was observed for $60 \mathrm{mM} \mathrm{H}_{2} \mathrm{O}_{2}$ in the absence of any catalyst. BPA removal increased monotonically with $\left[\mathrm{H}_{2} \mathrm{O}_{2}\right]$ for all loadings, spanning 10 to $90 \%$ removal for concentrations spanning $20-100 \mathrm{mM}$, highlighting the importance of hydroxyl radical $\left({ }^{\circ} \mathrm{OH}\right.$ ) chemistry (as evidenced by EPR spin trapping below). A volcano dependence on activity with copper loading was again observed, with the 2.5 wt\% Cu/TUD-1 offering the highest BPA removal in all cases, and achieving $95 \%$ degradation for $100 \mathrm{mM} \mathrm{H} \mathrm{H}_{2}$. This performance surpasses heterogeneous $\mathrm{Cu} / \mathrm{SBA}-15, \mathrm{Cu} / \mathrm{MCM}-41$ and $\mathrm{Cu} / \mathrm{SiO}_{2}$ catalysts possessing a common $2 \mathrm{wt} \%$ loading wherein $70 \%, 58 \%$ and $40 \% \mathrm{BPA}$ removal are reported respectively [28], and is almost comparable to that Cu-doped titania nanotubes [23] for which $100 \%$ BPA removal is claimed, although the presence of titania (a UV-active semiconductor) hinders comparison with the latter case wherein direct photocatalytic degradation may occur in addition to Fenton-like copper catalyzed oxidation. We note that in the case of azo dyes, homogeneous copper hydroxide nitrate catalysts exhibit comparable degradation activities [45], but undergo rapid 
deactivation through over-oxidation by $\mathrm{H}_{2} \mathrm{O}_{2}$. It should be noted that the solution $\mathrm{pH}$ decreased slightly from around 3.5 to 3.1 during the first $1 \mathrm{~h}$ of reaction, presumably due to the formation of small organic acids through BPA oxidative degradation catalyzed by hydroxyl radicals produced over the Cu/TUD-1 surface.

Table 2. Influence of $\mathrm{H}_{2} \mathrm{O}_{2}$ concentrations for BPA removal \% over different $\mathrm{Cu} / T U D-1$ catalysts.

\begin{tabular}{cccc}
\hline $\left.\mathbf{H}_{2} \mathrm{O}_{2}\right]^{\mathrm{a}}$ & \multicolumn{3}{c}{ BPA removal / \% } \\
/ $\mathbf{~ m M ~}$ & $\mathbf{0 . 9} \mathbf{w t} \% \mathbf{C u}$ & $\mathbf{2 . 5} \mathbf{w t} \% \mathbf{C u}$ & $\mathbf{5 . 4} \mathbf{~ w t ~ \% ~ C u}$ \\
\cline { 2 - 4 } 20 & 6 & 10 & 3 \\
40 & 34 & 54 & 25 \\
60 & 45 & 69 & 34 \\
80 & 59 & 80 & 42 \\
90 & 78 & 89 & 56 \\
100 & 86 & 95 & 65 \\
\hline
\end{tabular}

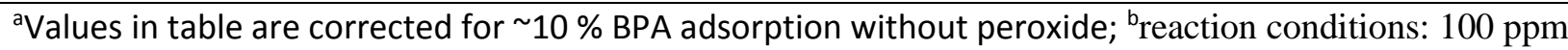
BPA, $0.1 \mathrm{~g}$ catalyst, $180 \mathrm{~min}$ reaction.

Additional spin trap experiments employing DMPO (5, 5-dimethyl-1-pyrroline N-oxide) as a radical quenching agent were undertaken to identify hydroxyl radical formation as shown in Figure 8 . The spectrum of pure DMPO coordinated to hydroxyl radicals exhibited the expected 1:2:2:1 signals indicative of DMPO-OH formation with a split center around $3400 \mathrm{G}[23,46]$. DMPO addition during BPA degradation over $2.5 \mathrm{wt} \% \mathrm{Cu} / \mathrm{TUD}-1$ resulted in a qualitatively similar, albeit weaker EPR signature 
spectrum for hydroxylated DMPO, confirming the generation of hydroxyl radicals during oxidative degradation of the Bisphenol.

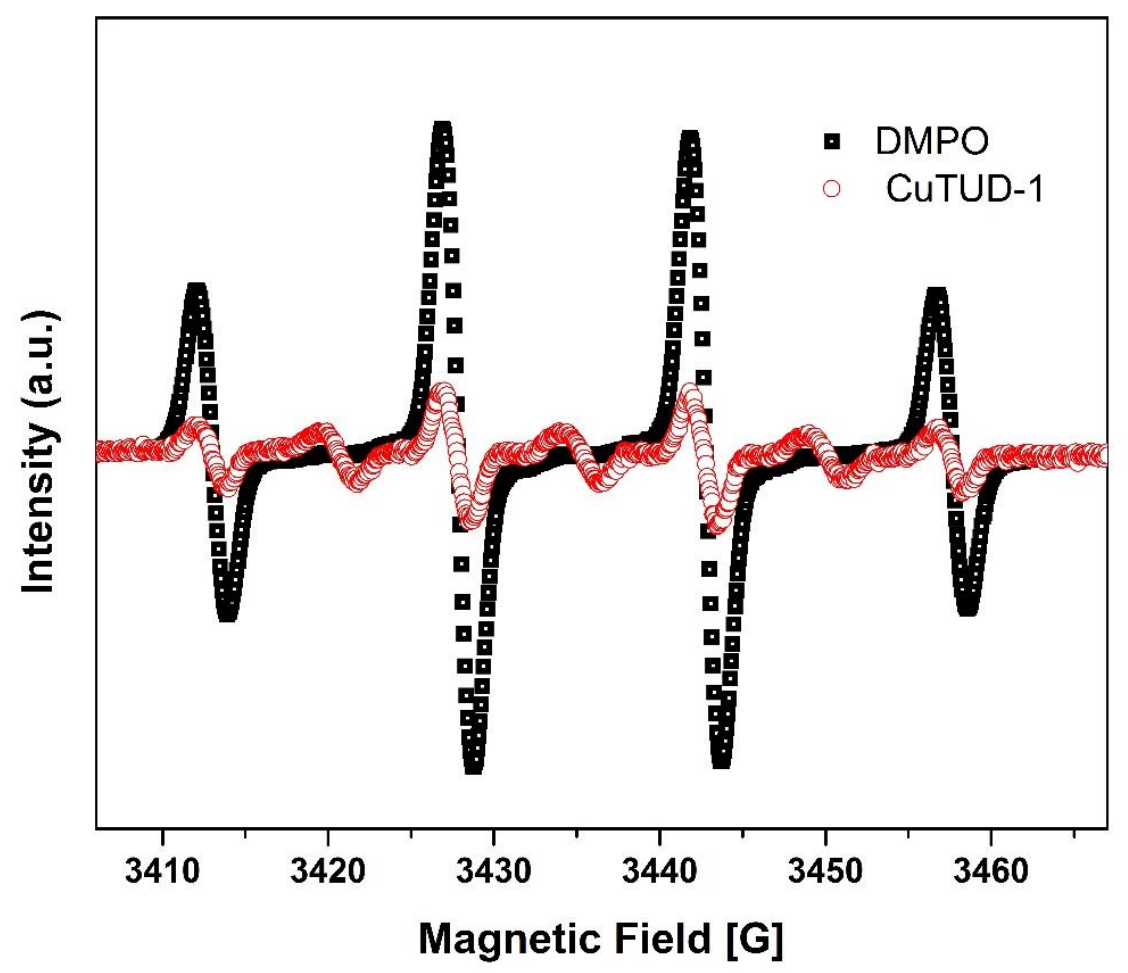

Figure 8. EPR spin trap spectra for pure DMPO and $2.5 \mathrm{wt} \% \mathrm{Cu} / \mathrm{TUD}-1$ in the presence of DMPO highlighting the formation of hydroxyl radicals. Reaction conditions: 100 ppm BPA, $0.1 \mathrm{~g} 2.5 \mathrm{wt} \%$ $\mathrm{Cu} / \mathrm{TUD}-1,90 \mathrm{mM} \mathrm{H} \mathrm{O}_{2}, 180$ min reaction.

Some insight into the nature and concentration of fluorophores present during BP degradation was subsequently obtained through excitation-emission matrix (EEM) fluorescence spectroscopy $[47,48]$. The reaction mixture before and after Fenton-like oxidative degradation of BPA over 2.5 wt\% Cu/TUD-1 was investigated by three dimensional fluorescence spectroscopy for excitation wavelengths spanning 200-400 nm, and the measurement of resulting emission profiles between 200 to $600 \mathrm{~nm}$ (Figure 9). 

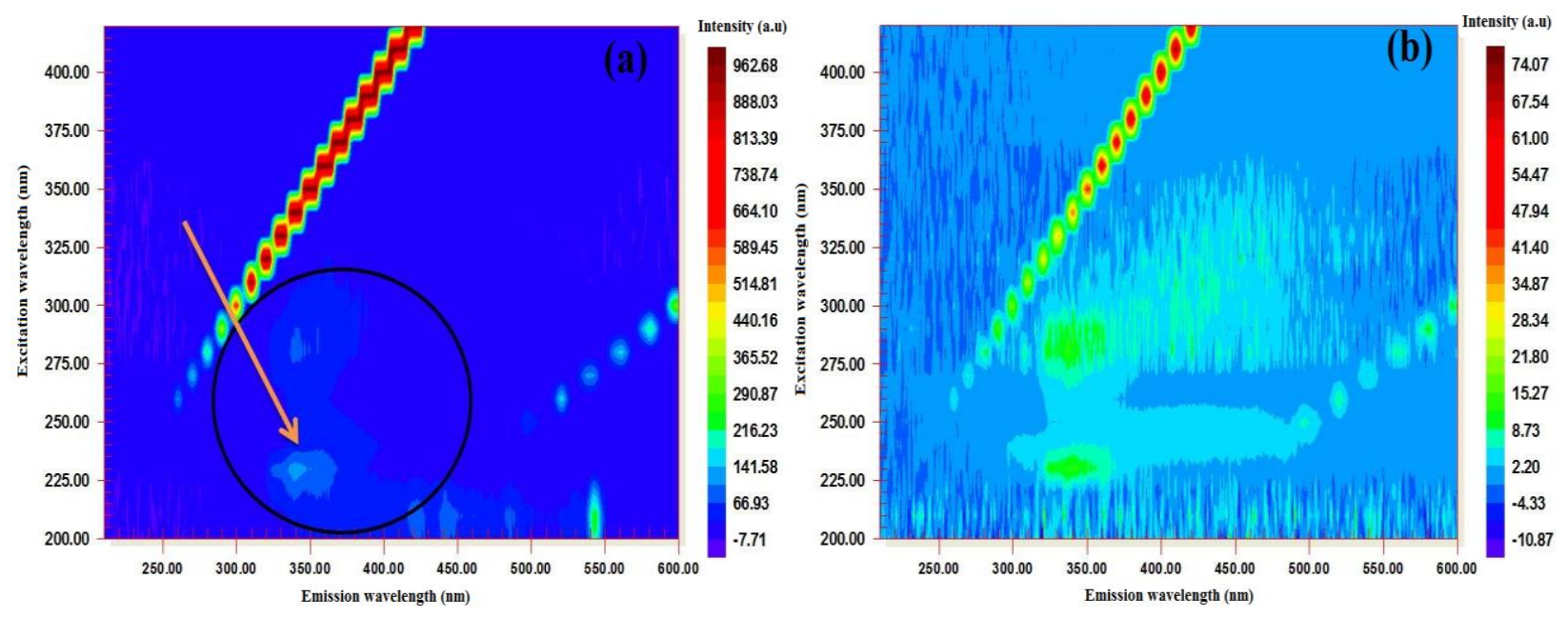

Figure 9. Excitation and emission matrix of (a) BPA and (b) 2.5 wt\% Cu/TUD-1 treated BPA. Reaction conditions: 100 ppm BPA, $0.1 \mathrm{~g} 2.5 \mathrm{wt} \% \mathrm{Cu} / \mathrm{TUD}-1,90 \mathrm{mM} \mathrm{H}_{2} \mathrm{O}_{2}, 180$ min reaction.

EEM spectra revealed strong bands between 325-375 $\mathrm{nm}$ for the parent BPA, indicative of its aromatic chromophores (Figure 9a). After reaction over 2.5 wt\% Cu/TUD-1, the intensity of emission peaks decreased dramatically for wavelengths between $325-520 \mathrm{~nm}$, consistent with loss of aromaticity (Figure 9b). A coincident red-shift in the wavelength of the features circled in Figure 9a is attributed to the inclusion of auxochromic groups as a result of ring opening associated with the fragmentation of the parent phenol into smaller non-aromatic compounds during oxidation or the elimination of hydroxyl groups from BPA [49-51]. A possible hydroxyl radical oxidation mechanism for BPA removal based on accepted heterogeneous Fenton chemistry is provided in Scheme S1.

The stability of $\mathrm{Cu} / \mathrm{TUD}-1$ catalysts towards $\mathrm{Cu}$ leaching was assessed through elemental analysis of the reaction solution after $2 \mathrm{~h}$ of oxidation (Table 3). All three copper loadings exhibited similar, extremely low amounts of leached copper during reaction, representing $<0.1 \%$ of the total copper present in each fresh catalyst.

Table 3. Elemental analysis of leached copper during reaction ${ }^{\mathrm{a}}$ 


\begin{tabular}{lll}
\hline Cu loading & Leached $\mathrm{Cu}^{\mathrm{b}}$ & BPA removal \\
/ wt\% & $/ \mathrm{mg} / \mathrm{L}$ & $/ \%$ \\
\hline 0.9 & 0.0032 & 80.3 \\
2.5 & 0.0027 & 90.4 \\
5.4 & 0.0029 & 68.1 \\
\hline
\end{tabular}

${ }^{\mathrm{b}}$ State experimental conditions; ${ }^{\mathrm{b}}$ Values obtained from AAS analysis

Catalyst reusability was explored for $2.5 \mathrm{wt} \% \mathrm{Cu} / \mathrm{TUD}-1$ for BPA degradation over 5 consecutive cycles (Figure 10), through the addition of fresh BPA to the reaction mixture every $120 \mathrm{~min}$. A constant BP removal efficiency of $91 \pm 2 \%$ was observed for every cycle, indicating negligible deactivation.

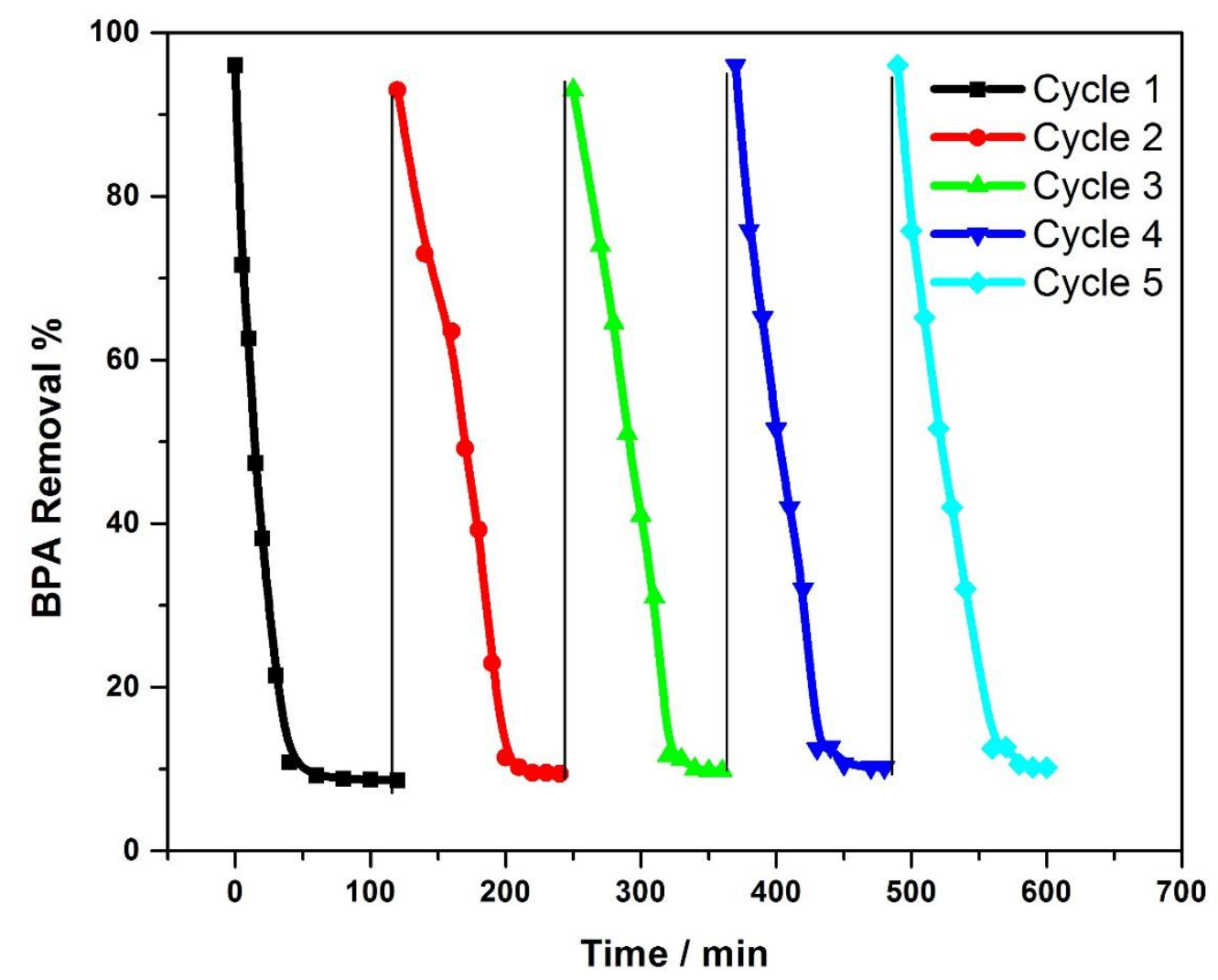

Figure 10. Stability of $2.5 \mathrm{wt} \% \mathrm{Cu} / \mathrm{TUD}-1$ catalyst after five cycles in BPA removal efficiency during the heterogeneous Fenton-like oxidation process. Reaction conditions: 100 ppm BPA, 0.1 g catalyst, $90 \mathrm{mM}$ $\mathrm{H}_{2} \mathrm{O}_{2}, 180$ min reaction. 
The order of reaction with respect to [BPA] was determined from regression analysis of the first $30 \mathrm{~min}$ reaction as shown in Figure S3. A plot of $\ln (\mathrm{BPA})_{0} /(\mathrm{BPA})_{\mathrm{t}}$ versus time revealed the expected first order dependence of degradation rate for all $\mathrm{Cu} / \mathrm{TUD}-1$ catalysts.

\section{Conclusion}

A family of copper modified TUD-1 catalysts were synthesized with Cu loadings between 0.9-5.4 wt\% employing TEG as a soft template. The resulting materials exhibited high surface areas and an amorphous, disordered mesopore network, containing isolated $\mathrm{Cu}^{2+}$ ions in a tetrahedral coordination (presumably within the silica framework) alongside $\mathrm{CuO}$ oligomers. High copper loadings favor the formation of $\mathrm{CuO}$ nanocrystallites dispersed across the TUD-1 support. Cu/TUD-1 is an excellent catalyst BPA oxidative degradation in the presence of $\mathrm{H}_{2} \mathrm{O}_{2}$, with the optimum 2.5 wt\% Cu/TUD-1 achieving 90.4 \% BPA removal in $180 \mathrm{~min}$. Spin trap EPR measurements confirm that oxidation occurs via the generation of ${ }^{\bullet} \mathrm{OH}$ radicals from $\mathrm{H}_{2} \mathrm{O}_{2}$, especially over isolated/oligomeric $\mathrm{Cu}^{2+}$ species, through a Fenton-like mechanism. Excitation-emission matrix fluorescence spectroscopy revealed that oxidation was accompanied by a loss of aromaticity and molecular fragmentation, while kinetic analysis confirmed that BPA degradation was first order in the pollutant independent of copper loading. Cu/TUD-1 exhibited negligible deactivation over five recycles, within minimal Cu leaching $(0.0027 \mathrm{mg} / \mathrm{L})$.

\section{Acknowledgements}

A.F.L. thanks the EPSRC for financial support (EP/K021796/1, EP/K029525/2). S.K. acknowledges the Royal Society and Science and Engineering Research Board for the award of a Royal Society-SERB

“Newton International Fellowship” . A.R acknowledges partial support from the joint National Science 
Foundation and Environmental Protection Agency program Networks for Sustainable Material Synthesis and Design (NSF-EPA 1339661).

\section{References}

[1] J.J. Pignatello, E. Oliveros, A. MacKay, Advanced oxidation processes for organic contaminant destruction based on the Fenton reaction and related chemistry, Crit. Rev. Environ. Sci. Technol. 36 (2006) 1-84.

[2] M. Muruganandham, R.P. Suri, M. Sillanpää, J.J. Wu, B. Ahmmad, S. Balachandran, et al., Recent Developments in Heterogeneous Catalyzed Environmental Remediation Processes, J. Nanosci. Nanotechnol. 14 (2014) 1898-1910.

[3] S.R. Pouran, A.A.A. Raman, W.M.A.W. Daud, Review on the application of modified iron oxides as heterogeneous catalysts in Fenton reactions, J. Clean. Prod. 64 (2014) 24-35.

[4] L.-A. Galeano, M.Á. Vicente, A. Gil, Catalytic Degradation of Organic Pollutants in Aqueous Streams by Mixed Al/M-Pillared Clays (M= Fe, Cu, Mn), Catal. Rev. 56 (2014) 239-287.

[5] M. Pereira, L. Oliveira, E. Murad, Iron oxide catalysts: Fenton and Fenton-like reactions-a review, Clay Miner. 47 (2012) 285-302.

[6] Q. Zhai, L. Zhang, X. Zhao, H. Chen, D. Yin, J.Li, A novel iron-containing polyoxometalate heterogeneous photocatalyst for efficient 4-chlorophennol degradation by $\mathrm{H} 2 \mathrm{O} 2$ at neutral $\mathrm{pH}$, Appl. Surf. Sci., 377 (2016) 17-22.

[7] S. R. Pouran, A. R. Abdul Aziz, W. M. A. W. Daud, Z. Embong, Niobium substituted magnetite as a strong heterogeneous Fenton catalyst for wastewater treatment, Appl. Surf. Sci., 351 (2015) 175187. 
[8]L. Zhou, J. Ma, H. Zhang, Y. Shao, Y. Li, Fabrication of magnetic carbon composites from peanut shells and its application as a heterogeneous Fenton catalyst in removal of methylene blue, Appl. Surf. Sci., 324 (2015) 490-498.

[9] S. Fathinia, M. Fathinia, A. A. Rahmani, A. Khataee, Preparation of natural pyrite nanoparticles by high energy planetary ball milling as a nanocatalyst for heterogeneous Fenton process, Appl. Surf. Sci., 327 (2015) 190-200.

[10] D. Yin, L. Zhang, X. Zhao, H. Chen, Q. Zhai, Iron-glutamate-silicotungstate ternary complex as highly active heterogeneous Fenton-like catalyst for 4-chlorophenol degradation, Chinese J. Catal., 36 (2015) 2203-2210.

[11] Z. Huang, P. Wu, B. Gong, S. Yang, H. Li, Z. Zhu, L. Cui, Preservation of glutamic acid-iron chelate into montmorillonite to efficiently degrade Reactive Blue 19 in a Fenton system under sunlight irradiation at neutral pH, Appl. Surf. Sci., 370 (2016) 209-217.

[12] M. Hartmann, S. Kullmann, H. Keller, Wastewater treatment with heterogeneous Fenton-type catalysts based on porous materials, J. Mater. Chem. 20 (2010) 9002-9017.

[13] N.H. Phu, T.T.K. Hoa, N. Van Tan, H.V. Thang, P. Le Ha, Characterization and activity of Fe-ZSM-5 catalysts for the total oxidation of phenol in aqueous solutions, Appl. Catal. B Environ. 34 (2001) 267-275.

[14] K. Parida, A.C. Pradhan, Fe/meso-Al2O3: An efficient photo-Fenton catalyst for the adsorptive degradation of phenol, Ind. Eng. Chem. Res. 49 (2010) 8310-8318.

[15] S. Karthikeyan, C.J. Magthalin, A.B. Mandal, and G. Sekaran, Controlled synthesis and characterization of electron rich iron (III) oxide doped nanoporous activated carbon for the catalytic oxidation of aqueous ortho phenylene diamine, RSC Adv. 4 (2014) 19183-19195. 
[16] I. Ursachi, A. Stancu, A. Vasile, Magnetic $\alpha-F e 2 O 3 / M C M-41$ nanocomposites: preparation, characterization, and catalytic activity for methylene blue degradation, J. Colloid Interface Sci. 377 (2012) 184-190.

[17] P. Shukla, S. Wang, H. Sun, H.-M. Ang, M. Tadé, Adsorption and heterogeneous advanced oxidation of phenolic contaminants using Fe loaded mesoporous SBA-15 and $\mathrm{H}_{2} \mathrm{O}_{2}$, Chem. Eng. J. 164 (2010) $255-260$.

[18] M.P. Pachamuthu, S. Karthikeyan, G. Sekaran, R. Maheswari, A. Ramanathan, Fenton-Type Oxidative Degradation of N,N-Diethyl-p-phenylenediamine by a Mesoporous Wormhole Structured FeTUD-1 Catalyst, CLEAN - Soil Air Water. 43 (2015) 375-381.

[19] H.C. Sutton, C.C. Winterbourn, On the participation of higher oxidation states of iron and copper in Fenton reactions, Free Radic. Biol. Med. 6 (1989) 53-60.

[20] M. Dükkancı, G. Gündüz, S. Yılmaz, R. Prihod'ko, Heterogeneous Fenton-like degradation of Rhodamine 6G in water using CuFeZSM-5 zeolite catalyst prepared by hydrothermal synthesis, J. Hazard. Mater. 181 (2010) 343-350.

[21] L. Parimala, J. Santhanalakshmi, CuO nanoparticles with biostabilizers for the catalytic decolorization of bromocresol green, crystal violet, methyl red dyes based on $\mathrm{H} 2 \mathrm{O} 2$ in aqueous medium, React. Kinet. Mech. Catal. 109 (2013) 393-403.

[22] D. Xu, F. Cheng, Q. Lu, P. Dai, Microwave Enhanced Catalytic Degradation of Methyl Orange in Aqueous Solution over $\mathrm{CuO} / \mathrm{CeO}_{2}$ Catalyst in the Absence and Presence of $\mathrm{H} 2 \mathrm{O} 2$, Ind. Eng. Chem. Res. 53 (2014) 2625-2632.

[23] R. Doong, S. Chang, C. Tsai, Enhanced photoactivity of Cu-deposited titanate nanotubes for removal of bisphenol A, Appl. Catal. B Environ. 129 (2013) 48-55. 
[24] X. Zhang, Y. Ding, H. Tang, X. Han, L. Zhu, N. Wang, Degradation of bisphenol A by hydrogen peroxide activated with CuFeO 2 microparticles as a heterogeneous Fenton-like catalyst: efficiency, stability and mechanism, Chem. Eng. J. 236 (2014) 251-262.

[25] F.L. Lam, A.C. Yip, X. Hu, Copper/MCM-41 as a highly stable and pH-insensitive heterogeneous photo-Fenton-like catalytic material for the abatement of organic wastewater, Ind. Eng. Chem. Res. 46 (2007) 3328-3333.

[26] S. Karthikeyan, D.D. Dionysiou, A.F. Lee, S. Suvitha, P. Maharaja, K. Wilson, and G. Sekaran, Hydroxyl radical generation by cactus-like copper oxide nanoporous carbon catalysts for microcystin-LR environmental remediation, Catal. Sci. Technol. 6 (2016) 530-544.

[27] L. Lyu, L. Zhang, C. Hu, Enhanced Fenton-like degradation of pharmaceuticals over framework copper species in copper-doped mesoporous silica microspheres, Chem. Eng. J. 274 (2015) 298306.

[28] M.P. Pachamuthu, V.V. Srinivasan, R. Maheswari, K. Shanthi, A. Ramanathan, The impact of the copper source on the synthesis of meso-structured Cu/TUD-1: a promising catalyst for phenol hydroxylation, Catal. Sci. Technol. 3 (2013) 3335-3342.

[29] S. Telalovic, A. Ramanathan, G. Mul, U. Hanefeld, TUD-1: synthesis and application of a versatile catalyst, carrier, material ..., J. Mater. Chem. 20 (2010) 642-658.

[30] G. Imran, M.P. Pachamuthu, R. Maheswari, A. Ramanathan, S.S. Basha, Catalytic activity of MnTUD1 for liquid phase oxidation of ethylbenzene with tert-butyl hydroperoxide, J. Porous Mater. 19 (2012) 677-682.

[31] M.P. Pachamuthu, V.V. Srinivasan, R. Maheswari, K. Shanthi, A. Ramanathan, Lewis acidic ZrTUD-1 as catalyst for tert-butylation of phenol, Appl. Catal. Gen. 462-463 (2013) 143-149. 
[32] M.P. Pachamuthu, R. Rajalakshmi, R. Maheswari, A. Ramanathan, Direct glycol assisted synthesis of an amorphous mesoporous silicate with framework incorporated Co 2+: characterization and catalytic application in ethylbenzene oxidation, RSC Adv. 4 (2014) 29909-29916.

[33] Water pollution in India, (2015). http://en.wikipedia.org/wiki/Water_pollution_in_India (accessed April 22, 2015).

[34] K.K. Selvaraj, G. Shanmugam, S. Sampath, D.G. Joakim Larsson, B.R. Ramaswamy, GC-MS determination of bisphenol A and alkylphenol ethoxylates in river water from India and their ecotoxicological risk assessment, Ecotoxicol. Environ. Saf. 99 (2014) 13-20.

[35] B.S. Rubin, Bisphenol A: an endocrine disruptor with widespread exposure and multiple effects, J. Steroid Biochem. Mol. Biol. 127 (2011) 27-34.

[36] F.S. vom Saal, S.C. Nagel, B.L. Coe, B.M. Angle, J.A. Taylor, The estrogenic endocrine disrupting chemical bisphenol A (BPA) and obesity, Mol. Cell. Endocrinol. 354 (2012) 74-84.

[37] D. Tiwari, J. Kamble, S. Chilgunde, P. Patil, G. Maru, D. Kawle, et al., Clastogenic and mutagenic effects of bisphenol A: an endocrine disruptor, Mutat. Res. Toxicol. Environ. Mutagen. 743 (2012) 83-90.

[38] K. M, H.A. Salam, R. Sivaraj, V. R, Detection of Bisphenol-A in various environment samples collected from Tamil Nadu, India by solid-phase extraction and GC analysis, Adv. Bioresearch. 4 (2013) 59-64.

[39] I. Arslan-Alaton, T. Olmez-Hanci, Advanced Oxidation of Endocrine Disrupting Compounds: Review on Photo-Fenton Treatment of Alkylphenols and Bisphenol A, in: Green Technol. Wastewater Treat., Springer, 2012: pp. 59-90.

[40] S. Chouhan, S.K. Yadav, J. Prakash, S.P. Singh, Effect of Bisphenol A on human health and its degradation by microorganisms: a review, Ann. Microbiol. 64 (2014) 13-21. 
[41] J. Li, L. Jiang, X. Liu, J. Lv, Adsorption and aerobic biodegradation of four selected endocrine disrupting chemicals in soil-water system, Int. Biodeterior. Biodegrad. 76 (2013) 3-7.

[42] R. Huang, Z. Fang, X. Yan, W. Cheng, Heterogeneous sono-Fenton catalytic degradation of bisphenol $\mathrm{A}$ by $\mathrm{Fe}_{3} \mathrm{O}_{4}$ magnetic nanoparticles under neutral condition, Chem. Eng. J. 197 (2012) 242-249.

[43] A. Ramanathan, M.C. Castro Villalobos, C. Kwakernaak, S. Telalovic, U. Hanefeld, Zr-TUD-1: A Lewis Acidic, Three-Dimensional, Mesoporous, Zirconium-Containing Catalyst, Chem. - Eur. J. 14 (2008) 961-972.

[44] R. Anand, R. Maheswari, U. Hanefeld, Catalytic properties of the novel mesoporous aluminosilicate AITUD-1, J. Catal. 242 (2006) 82-91.

[45] Y. Zhan, X. Zhou, B. Fu, Y. Chen, Catalytic wet peroxide oxidation of azo dye (Direct Blue 15) using solvothermally synthesized copper hydroxide nitrate as catalyst, J. Hazard. Mater., 187 (2011) 348354.

[46] P. Bilski, K. Reszka, M. Bilska, C. F. Chignell, Oxidation of the Spin Trap 5,5-Dimethyl-1pyrroline N-Oxide by Singlet Oxygen in Aqueous Solution, J. Am. Chem. Soc. 118 (1996) 13301338.

[47] R. Henderson, A. Baker, K. Murphy, A. Hambly, R. Stuetz, S. Khan, Fluorescence as a potential monitoring tool for recycled water systems: A review, Water Res. 43 (2009) 863-881.

[48] R. Hao, H. Ren, J. Li, Z. Ma, H. Wan, X. Zheng, et al., Use of three-dimensional excitation and emission matrix fluorescence spectroscopy for predicting the disinfection by-product formation potential of reclaimed water, Water Res. 46 (2012) 5765-5776.

[49] S. Valencia, J.M. Marín, G. Restrepo, F.H. Frimmel, Application of excitation-emission fluorescence matrices and UV/Vis absorption to monitoring the photocatalytic degradation of commercial humic acid, Sci. Total Environ. 442 (2013) 207-214. 
[50] S. Karthikeyan, R. Boopathy, G. Sekaran, In situ generation of hydroxyl radical by cobalt oxide supported porous carbon enhance removal of refractory organics in tannery dyeing wastewater, J. Colloid Interface Sci. 448 (2015) 163-174.

[51] U. Aruldoss, L. J. Kennedy, J. J. Vijaya, G. Sekaran, Photocatalytic degradation of phenolic syntan using $\mathrm{TiO}_{2}$ impregnated activated carbon, J. Colloid Interface Sci. 355 (2011) 204-209. 
Graphical Abstract

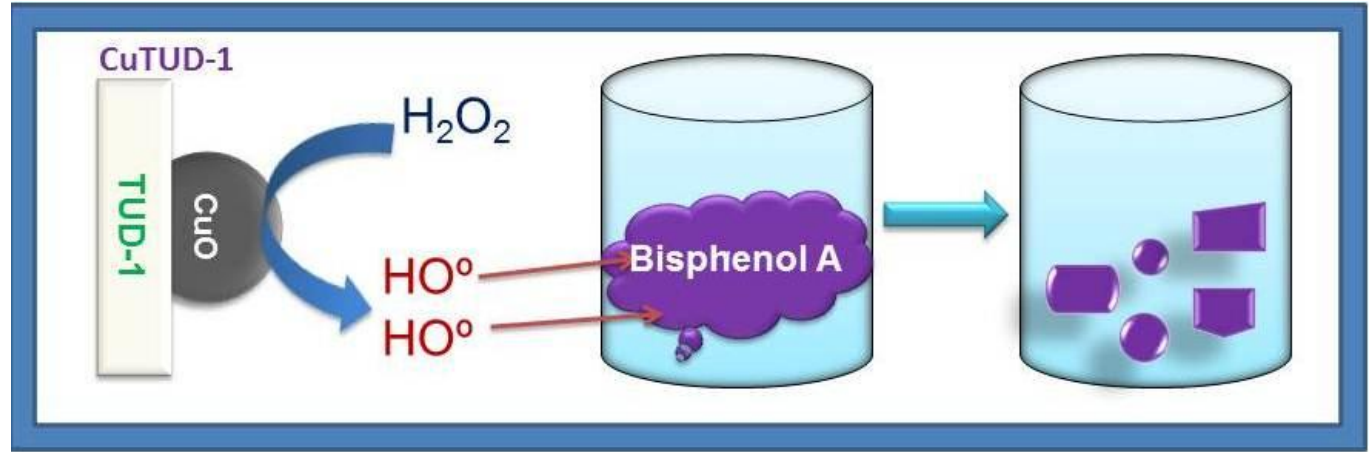

